\title{
CUERSITHYRIS (BRACHIOPODA, TEREBRATULIDA) DEL JURÁSICO INFERIOR DE LA CORDILLERA IBÉRICA, ESPAÑA
}

\author{
Ana RODRIGO' y $M^{a}$ José COMAS-RENGIFO² \\ ' Museo Geominero (ITGE). Ríos Rosas, 23. 28003 Madrid. \\ ? Dpto.-U.E.I. de Paleontología. Facultad de Ciencias Geológicas e Instituto de \\ Geología Económica CS!C-UCM. Ciudad Universitaria. 28040 Madrid.
}

Rodrigo, A. y Comas-Rengifo, M.J. 1998. Cuersithyris (Brachiopoda, Terebratulida) del Jurásico Inferior de la Cordillera Ibérica, España. [Cuersithyris (Brachiopoda, Terebratulida) of the Lower Jurassic in the Iberian Range, Spain]. Revista Española de Paleontología, 13 (1), 1-15. ISSN 0213-6937.

\begin{abstract}
Specimens of Cuersithyris are numerous in the carbonatic sediments of the Upper Sinemurian (Raricostatum Zone)-Lower Pliensbachian (Ibex Zone, Masseanum Subzone) in the Iberian Range. Cuersithyris genus has a massive umbo, incurved, very small foramen, well-marked growth lines, middle sulcus on dorsal valve and welldeveloped umbonal callosities. The characterization of the species radstockiensis and davidsoni has been done out of one thousand specimens from seven localities in the Iberian Range and one in Mallorca (Baleares Islands). The differentiation among two species has been done taking into account the outline, convexity of valves, development of the dorsal middle sulcus, transversal section, umbonal thickening, morphology of the cardinal process, cardinal plates and transversal band. The study of $C$. davidsoni internal and external characters, as well as its stratigraphic range, let us consider it as an independent species which includes in its variability the forms attributed, up to date, to $C$. cuersensis. The register of the genus is limited to South-western European basins where $C$. davidsoni and $C$. radstockiensis have been used as zonal indexes. During the Upper Sinemurian-Lower Pliensbachian interval, brachiopod associations are typically boreal and belong to the European Province.
\end{abstract}

Keywords: Cuersithyris, Terebratulida, Brachiopoda, Lower Jurassic, Iberian Range, Spain.

\section{RESUMEN}

Los ejemplares de braquiópodos del género Cuersithyris son muy numerosos en los materiales carbonatados del Sinemuriense superior (Zona Raricostatum)-Pliensbachiense inferior (Zona Ibex, Subzona Masseanum) de la Cordillera Ibérica. La caracterización de las especies se ha realizado a partir de ejemplares procedentes de siete localidades de la Cordillera Ibérica y una de Mallorca. El género Cuersithyris, poco estudiado hasta el momento, se caracteriza por un umbo masivo, recurvado, foramen muy pequeño, líneas de crecimiento marcadas, surco medio en la valva dorsal y callosidades umbonales muy desarrolladas. La diferenciación de las especies $C$. radstockiensis y C. clavidsoni se ha realizado teniendo en cuenta el contorno, grado de convexidad de las valvas, desarrollo del surco medio dorsal, sección transversal, engrosamiento umbonal, morfología del proceso cardinal, placas cardinales y bandeleta transversal. La variabilidad reconocida para la especie $C$. clavidsoni incluye las formas atribuidas hasta el momento a $C$. cuersensis. El registro del género se restringe a las cuencas del suroeste de Europa, donde se ha detectado un relevo relativamente rápido de estas especies. Durante el intervalo de tiempo considerado, las asociaciones de braquiópodos que se han reconocido muestran afïnidades con la Provincia Europea.

Palabras clave: Cuersithyris, Terebratulida, Brachiopoda, Jurásico Inferior, Cordillera Ibérica, España.

\section{INTRODUCCIÓN}

El estudio de los braquiópodos del Jurásico Inferior en la Cordillera Ibérica es relativamente reciente, de manera que no son muy numerosos los trabajos que abordan aspectos relacionados con este grupo tan abundante de invertebrados. Entre ellos, cabe destacar los de Goy y Robles (1971), Goy (1974), Comas-Rengifo y Goy (1975, 1978), García-Joral y Goy (1984), Goy et al. (1984), Comas-Rengifo (1985), García-Joral (1986), Soler-Olivé (1986), Rodrigo (1994) y Comas-Rengifo y Rodrigo (1995).

Este trabajo se centra en la revisión de un significativo grupo de terebratúlidos del Jurásico Inferior 

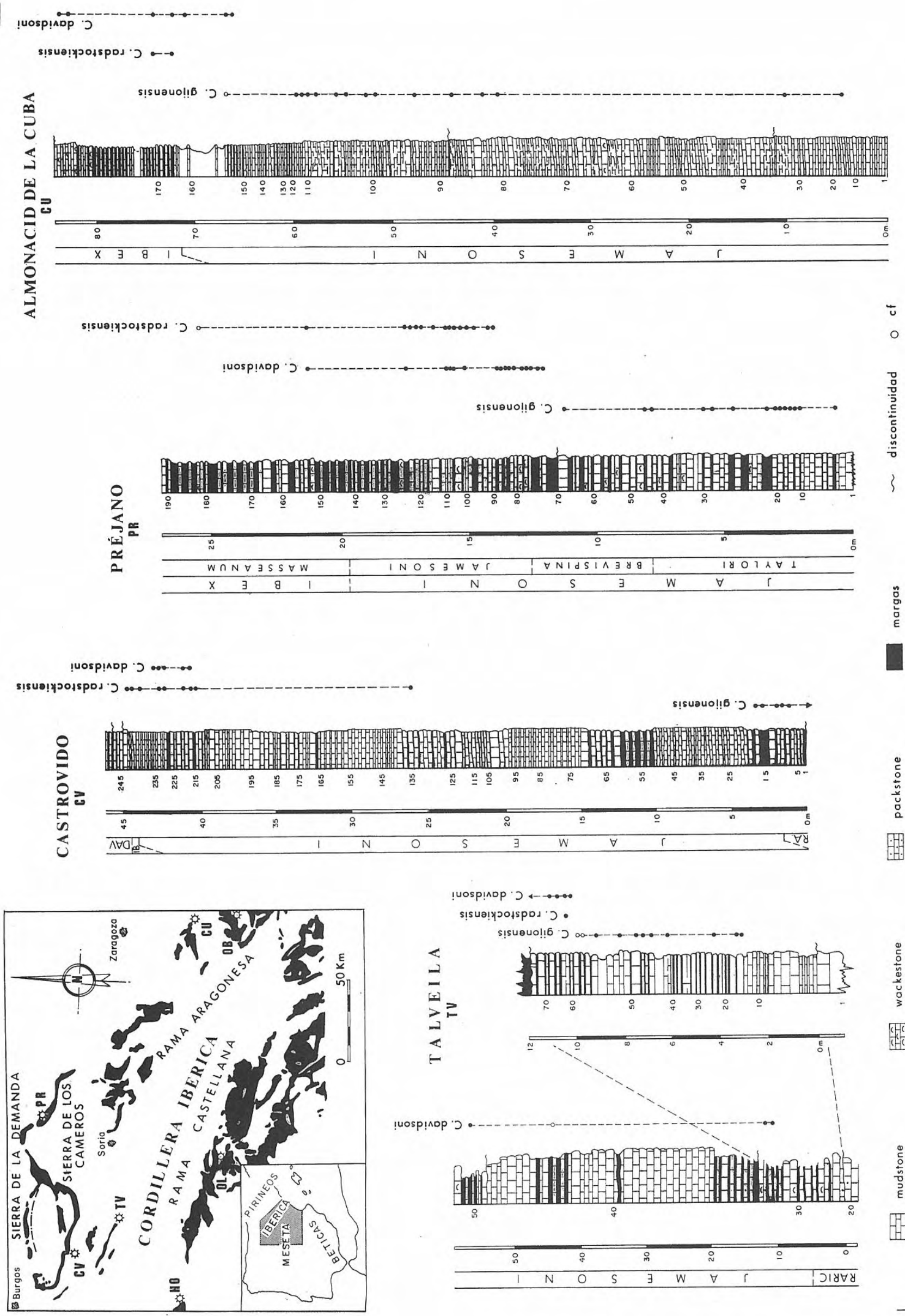

!uospinop $2, \ldots$

s!̣ua!yjołspod כ •

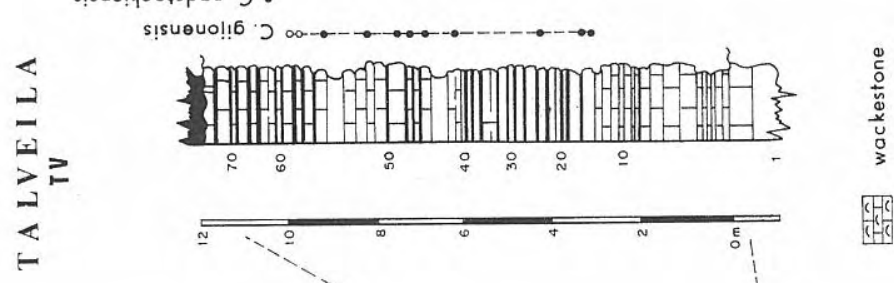

!uosp!nop ว

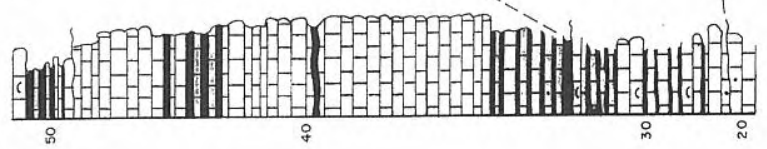

$\stackrel{0}{c}$
$\frac{0}{5}$
$\frac{5}{5}$
$\stackrel{5}{E}$

\begin{tabular}{|c|c|c|c|c|c|c|c|c|}
\hline : & & o & & "욤 & & $\stackrel{\circ}{\circ}$ & & 0 \\
\hline 1 & $\mathrm{~N}$ & 0 & $\mathrm{~s}$ & $\exists$ & $w$ & $\forall$ & r & ग४甘y \\
\hline
\end{tabular}


recogidos en diversos puntos de la Cordillera Ibérica. La elección de las secciones estratigráficas de las que procede el material responde, por una parte, al buen control estratigráfico que de ellas se tenía por los estudios previos basados en ammonoideos y, por otra, a la gran abundancia y variedad de braquiópodos existente en los materiales carbonatados del Jurásico Inferior. Esto nos ha permitido realizar estudios morfológicos, biométricos y estadísticos que han resultado de gran interés paleontológico, puesto que con ellos se han podido resolver algunas atribuciones genéricas y específicas que no eran bien conocidas. Además, la abundancia de ejemplares en los materiales de la parte inferior del Pliensbachiense inferior de la Cordillera Ibérica ha permitido comparar las propuestas bioestratigráficas basadas en braquiópodos establecidas por diversos autores, no sólo en la Cordillera Ibérica, sino también en otras áreas de Europa Occidental.

El género Cuersithyris Alméras y Moulan, 1982 incluye cuatro especies: Cuersithyris gijonensis (Dubar, 1925), que ha sido objeto de un estudio anterior por Comas-Rengifo y Rodrigo (1995), Cuersithyris radstockiensis (Davidson, 1876), Cuersithyris davidsoni (Haime, 1855) y Cuersithyris provincialis (Deslongchamps, 1873). Su registro estratigráfico abarca desde el Sinemuriense superior (Zona Raricostatum), con la aparición de la especie $C$. gijonensis, hasta el Toarciense inferior (Zona Bifrons, Subzona Sublevisoni), con la presencia de $C$. provincialis que, por el momento, no ha sido registrada en los materiales del Jurásico Inferior de la Cordillera Ibérica. La distribución estratigráfica de $C$. davidsoni y $C$. radstockiensis es bastante restringida, por lo que dichas especies han sido utilizadas como índices zonales para España ( $C$. davidsoni) y Francia ( $C$. davidsoni y $C$. radstockiensis).

Por lo que respecta a su distribución geográfica, $C$. davidsoni sólo ha sido registrada en las cuencas del SO de Europa, al igual que $C$. gijonensis, mientras que $C$. radstockiensis presenta una distribución más amplia, habiéndose citado también en Portugal y Gran Bretaña (Goy et al., 1984, Ager, 1990 y Alméras et al., 1991).

El estudio de las características internas y externas de C. davidsoni, así como la delimitación de su distribución estratigráfica, ha permitido considerarla como una especie independiente que incluye en su variabilidad las formas atribuidas hasta el momento a $C$. cuersensis por Alméras y Moulan (1982). Se ha mantenido el nombre de davidsoni para esta especie, respetando su prioridad.

\section{ESTRATIGRAFíA}

El material estudiado se ha recogido en siete secciones estratigráficas de la Cordillera Ibérica (Fig. 1). Dichas secciones son: Préjano (PR), Castrovido (CV) y Talveila
(TV) en el Sector Septentrional; Honrubia de la Cuesta (HO) y La Ventosa del Ducado (OL) en la Rama Castellana; y Almonacid de la Cuba (CU) y Obón (OB) en la Rama Aragonesa. En la figura 1 sólo se han representado las secciones en las que los ejemplares proceden de numerosos niveles estratigráficos ( $\mathrm{PR}, \mathrm{CV}, \mathrm{TV}$ y $\mathrm{CU})$, mientras que en las restantes localidades de la Cordillera Ibérica (HO, OL y OB) el registro es puntual. Estos afloramientos abarcan una extensa área en el ámbito de la Cordillera Ibérica, permitiendo el estudio de formas registradas en materiales pertenecientes a las Formaciones Cuevas Labradas, Préjano y Almonacid de la Cuba, y depositados en condiciones sedimentarias diferentes.

A continuación se describen brevemente las características litológicas de las secciones estratigráficas consideradas:

Corte de Préjano. Se sitúa al NE de la Sierra de la Demanda, corresponde a la provincia de Logroño y fue descrito por Mensink (1965) y Comas-Rengifo (1985). En la sección del Pliensbachiense inferior de Préjano se han reconocido cinco tramos litológicos (Comas-Rengifo, 1985) constituidos por una alternancia de calizas de color negro o gris, generalmente compactas y de aspecto irregular, con niveles de margas y/o margocalizas. Tanto las margas como las calizas aparecen constituyendo capas de pequeño espesor. En esta sección los braquiópodos son muy abundantes.

Corte de Castrovido. Se sitúa al S de la Sierra de la Demanda y al NO de la Sierra de Urbión, en la provincia de Burgos. Ha sido estudiado por numerosos autores, entre los que cabe destacar a Mensink (1965), Gil y Zubieta (1978), Comas-Rengifo (1979, 1985), García-Joral (1986) y ComasRengifo et al. (1988). Corresponde a una alternancia de calizas, margas y calizas margosas, con un predominio general de los materiales más carbonatados sobre los margosos.

Corte de Talveila. Se ubica al S de la Sierra de Urbión y pertenece a la provincia de Soria. Fue descrito por primera vez por Comas-Rengifo y Yébenes (1988), aunque Ureta y Goy (1986) aportaron datos importantes acerca del tránsito Toarciense-Aaleniense. Las facies son fundamentalmente calcáreas, estando concentrados los niveles con Cuersithyris en el tramo D de Comas-Rengifo y Yébenes (op. cit.), que corresponde a una alternancia de calizas y margas.

Corte de Honrubia de la Cuesta. Se localiza al N de la Sierra de Guadarrama y al S de la Sierra de Pela, en la provincia de Segovia. Ha sido estudiado y descrito por San Miguel de la Cámara (1951) y Comas-Rengifo (1985), y en él sólo se ha reconocido una especie dentro del género Cuersithyris, recogida en el tramo litológico C, que corresponde a una alternancia de calizas y margas.

Corte de La Ventosa del Ducado. Se sitúa al NE del pueblo de Jadraque y pertenece a la provincia de Guadalajara. Fue estudiado por Comas-Rengifo (1985). Las facies son fundamentalmente calizas masivas, y el género

Figura 1. Esquema de situación de los afloramientos del Jurásico Inferior de la Cordillera Ibérica (en trama oscura) y columnas estratigráficas de algunas de las localidades estudiadas. PR=Préjano (Logroño), CV=Castrovido (Burgos), TV=Talveila (Soria), HO=Honrubia de la Cuesta (Segovia), OL=La Ventosa del Ducado (Guadalajara) y CU=Almonacid de la Cuba (Zaragoza). 

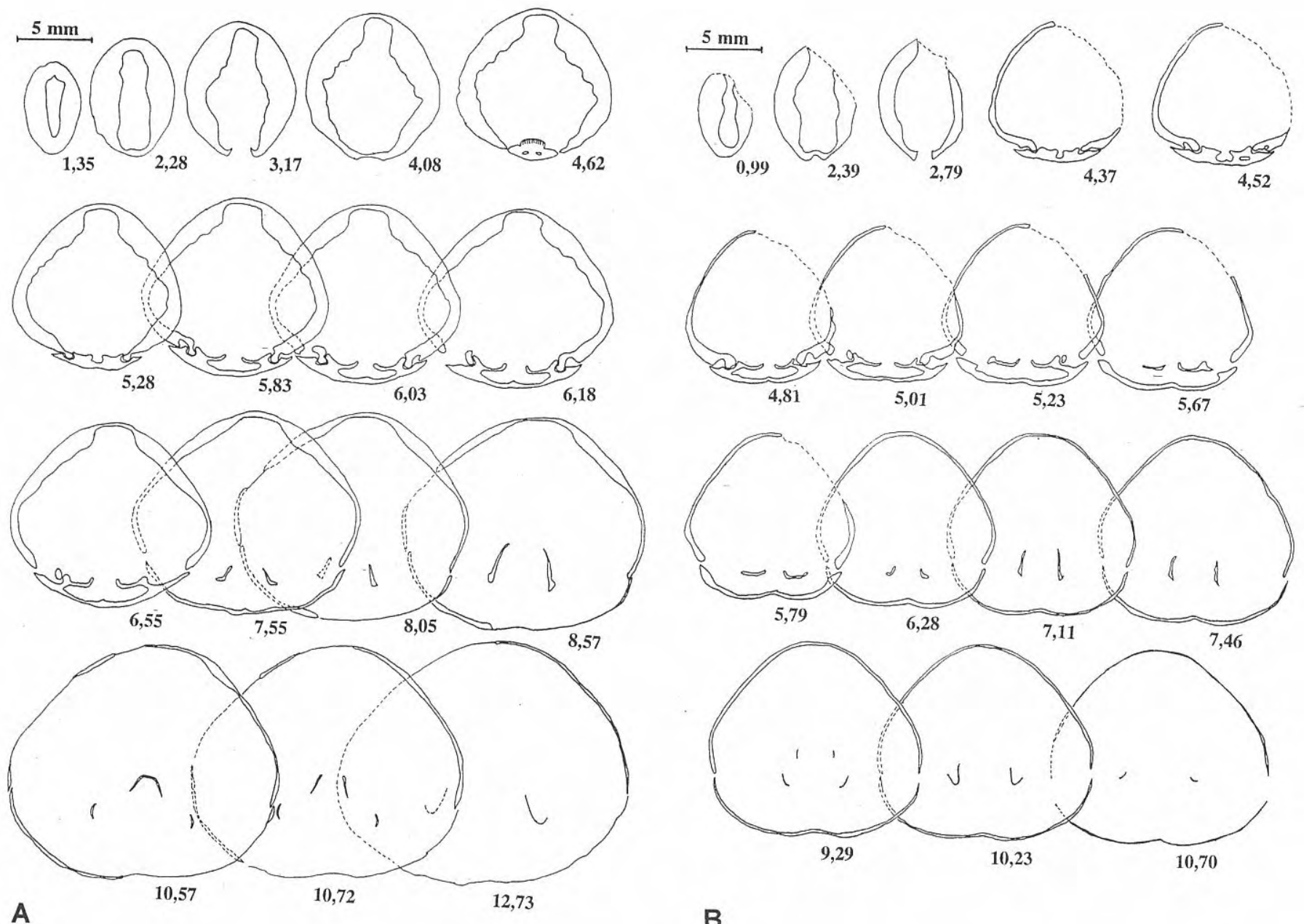

B

Figura 2. Cuersithyris davidsoni. A: Secciones seriadas del ejemplar MU-9B/7 (Lám. I, fig. 6 a-c). Sa Moleta. Zona Jamesoni, Subzona Jamesoni; B: Secciones seriadas del ejemplar CVI-173/3 (Lám. I, fig. 3 a-c). Castrovido. Zona Jamesoni.

Cuersithyris sólo se ha reconocido en cuatro niveles que corresponden a los dos primeros tramos de la columna estratigráfica.

Corte de Almonacid de la Cuba. Se sitúa al NE de la Sierra de Cucalón y al SE de la Sierra de la Muela. Corresponde a la provincia de Zaragoza. Fue descrito por Sequeiros et al. (1978) y por Comas-Rengifo (1985). En la base se encuentran facies micríticas y hacia el techo de la serie aparece una alternancia de calizas y margas.

Corte de Obón. Se localiza al NE del pueblo de Montalbán y pertenece a la provincia de Zaragoza. Esta sección fue descrita por Mouterde (1971), Mouterde et al. (1978) y Comas-Rengifo (1985). Está formado por una alternancia de calizas y calizas margosas fosilíferas.

Además de todo el material citado y con el fin de poder realizar comparaciones con ejemplares de $C$. davidsoni procedentes de la localidad tipo, se ha analizado una muestra de la sección de Sa Moleta (MU), que pertenece al Dominio de la Sierra Norte de la isla de Mallorca. El Jurásico de Mallorca ha sido estudiado por diversos autores, destacando los trabajos de Colom (1975) y Álvaro et al. (1984, 1989).

\section{SISTEMÁTICA}

ORDEN TEREBRATULIDA Waagen, 1883 Superfamilia TEREBRATULACEA Gray, 1840

Familia Terebratulidae Gray, 1840

Subfamilia Terebratulinae Gray, 1840

Género Cuersithyris Almerás y Moulan, 1982

Especie tipo: Terebratula davidsoni Haime, 1855 (Lám. 15, figs. 6a-d).

Otras especies asignadas: Cuersithyris cuersensis Alméras y Moulan, 1982 (Lám. 1, figs. 1-10, 13; Lám. 2, figs. 5, 15); Terebratula punctata Sowerby var. radstockiensis Davidson, 1876 (Sup., Lám. 16, figs. 14-18); Terebratula davidsoni Haime var. elongata Dubar, 1925 (Lám. 3, fig. 24); Terebratula davidsoni Haime var. gijonensis Dubar, 1925 (Lám. 4, figs. 8-13); Terebratula provincialis Deslongchamps, 1873 (Lám. 84).

\section{Observaciones}

En los últimos años ha existido una gran controversia 
acerca de la caracterización de los géneros Lobothyris y Cuersithyris. Este hecho produjo un notable desacuerdo entre la escuela francesa, representada por Alméras y colaboradores, y la escuela británica, representada por Ager. En 1917, Buckman definió el género Lobothyris incluyendo las especies Terebratula davidsoni Haime y Terebratula radstockiensis Davidson. Sin embargo, Muir-Wood (1934) discute esta clasificación en su trabajo acerca de las estructuras internas de algunos braquiópodos mesozoicos, llegando a la conclusión de que un estudio detallado de ambas especies indica que no pertenecen a Lobothyris sino a algún otro género. La distribución estratigráfica que Buckman estableció para $T$. davidsoni y $T$. radstockiensis es, respectivamente, "Domeriense" y "Charmouthiense".

Casi medio siglo después del trabajo de Muir-Wood (op. cit.), Alméras y Moulan (1982) realizaron una monografía sobre los terebratúlidos del Jurásico Inferior de Provenza (Francia). En este trabajo llevaron a cabo un estudio paleontológico de siete géneros y veinte especies francesas, concluyendo con una síntesis bioestratigráfica, paleoecológica y filogenética. Estos autores consideraron separados los géneros Cuersithyris y Lobothyris, dando para el primero una distribución estratigráfica desde el Sinemuriense superior al Toarciense inferior (parte superior de la Zona Bifrons, Subzona Sublevisoni) y para Lobothyris, desde el Pliensbachiense hasta el Toarciense superior.

La especie Terebratula radstockiensis Davidson, 1876 fue incluida dentro del género Cuersithyris por Alméras y Moulan (op. cit.). Estos autores designaron como lectotipo al ejemplar original de Davidson (1876, Lám. 16, fig. 14); sin embargo, Ager (1990) no reconoce la existencia del género Cuersithyris entre los terebratú-lidos del Jurásico Inferior británico, considerando como lectotipo de Lobothyris radstockiensis el figurado por Davidson (1876, Lám. 16, fig. 15). Así, establece las posibles relaciones entre las distintas especies de Lobothyris para el Jurásico Inferior y Medio de Gran Bretaña, situando el origen de la especie Lobothyris radstockiensis en el Sinemuriense. Además, sugiere la posibilidad de que los restantes Lobothyris del Jurásico Inferior [L. punctata subpunctata (Davidson), L. punctata edwardsii (Davidson), L. punctata punctata (Sowerby), L. punctata clevelandensis Ager, L. haresfieldensis (Davidson) y L. bucklandi (Davidson)] derivaran de L. radstockiensis.

Por otro lado, Ager (1990) y Alméras y Moulan (1982) dan la misma descripción de los caracteres externos e internos para L. radstockiensis como, por ejemplo: conchas globosas, alargadas, más equidimensionales que las otras especies en relación a la anchura y al espesor, con comisura frontal rectimarginada y ligeramente surcada; el umbo es incurvado y el foramen de muy pequeño tamaño para un terebratúlido. En cuanto a los caracteres internos, se observa una concha muy gruesa (interpretado por Ager como consecuencia de un crecimiento secundario) y la fusión completa del proceso cardinal. Para Ager (op. cit.), la distribución de $L$. radstockiensis se restringe al área de Radstock (Gran Bretaña).
En conclusión, Ager (op. cit.) no acepta el género Cuersithyris para la especie radstockiensis, incluyendo tal especie dentro del género Lobothyris, mientras que Alméras y Moulan (1982) consideran a ambos géneros separados. En la Cordillera Ibérica ha sido reconocida la presencia de especies de ambos géneros con caracteres externos e internos significativamente diferentes. Sin embargo, aparecen juntos en muchas ocasiones.

\section{Distribución estratigráfica y geográfica}

La distribución estratigráfica de Cuersithyris comprende desde el Sinemuriense superior (Zona Raricostatum), con la aparición de $C$. gijonensis, hasta el Toarciense inferior (Zona Bifrons, Subzona Sublevisoni), con la presencia de $C$. provincialis.

En relación a la distribución geográfica, hasta el momento se han encontrado ejemplares del género en Francia (Var, Bouches-du Rhône, Aveyron, Lozère); Gran Bretaña (alrededores de Radstock); y España (Baleares, Asturias, Cataluña y Cordillera Ibérica).

\section{Cuersithyris davidsoni (Haime, 1855) Lámina I, figs. 2-7}

* 1855 Terebratula davidsoni Haime, p. 745, Lám. 15, figs. $6 a, b, c, d$.

pars 1862 Terebratula subovoides, Deslongchamps (non Roemer), Lám. 37, figs. 5,9; Lám. 38, fig. 2.

pars 1862 Terebratula punctata Sowerby: Deslongchamps, Lám. 40, fig. 8.

pars 1925 Terebratula davidsoni variedad gibbosa, n.v.: Dubar, Lám. 3, figs. 12, 14, 17 y 22.

pars 1925 Terebratula davidsoni Haime: Dubar, p. 292296; Lám. 3, figs. 25-27; Lám. 4, figs. 3-7.

pars 1929 Terebratula punctata Sowerby var. davidsoni Haime: Lanquine, p. 139; Lám. 2, fig. 9.

pars 1931 Terebratula davidsoni Haime: Dubar, p. 38-41; Lám. 5, figs. 1-4.

pars 1947 Terebratula davidsoni Haime: Choffat, p. 12-14; Lám. 4, figs. 8, 10, 11.

pars 1974 "Terebratula” davidsoni Haime: Goy, p. 742; Lám. 102, figs. 1, 3.

1975 Terebratula davidsoni Haime: Colom, p. 90, figs. 4-6.

1982 Cuersithyris cuersensis Alméras y Moulan, p. 322; Lám. 1, figs. 1-10, p. 324, Lám. 2, fig. 15.

1982 Terebratula (Lobothyris?) davidsoni Haime: Alméras y Moulan, p. 322, figs. 11,12.

Existen muchas referencias a la especie Terebratula davidsoni en Buckman (1917), Suárez-Vega (1974), Colom (1975), Goy y Robles (1975), Alméras y Moulan (1979) y Comas-Rengifo (1985), aunque no se han incluido todas las citas para no hacer excesivamente larga la sinonimia. Después del trabajo de Alméras y Moulan (1982), la primera referencia española a la especie Cuersithyris? davidsoni aparece en Goy et al. (1984).

Ejemplar tipo: Alméras y Moulan (op. cit.) consideran 
como lectotipo el ejemplar del Jurásico Inferior de Sóller (Sa Moleta, Mallorca) figurado por Haime (1855, p. 794, Lám. 15 , figs. $6 \mathrm{~b}$ y $6 \mathrm{c})$.

\section{Material}

El estudio de la especie Cuersithyris davidsoni (Haime, 1855) se ha realizado sobre un total de 319 ejemplares distribuidos en siete localidades de la Cordillera Ibérica, además de 23 ejemplares procedentes de la localidad tipo (Tabla 1). Todo el material está depositado en el Departamento de Paleontología, Facultad de Ciencias Geológicas (UCM).

\section{Descripción}

Caracteres externos. C. davidsoni presenta una longitud muy variable, desde $9,34 \mathrm{~mm}$ hasta $34,33 \mathrm{~mm}$. El contorno puede ser desde cordiforme a ovalado, o incluso subpentagonal. Las valvas son desigualmente convexas: la peduncular es siempre más convexa que la braquial. En los estadios juveniles las morfologías son normalmente planoconvexas. Los individuos cordiformes muestran la máxima anchura situada hacia la mitad de la longitud y en las morfologías ovaladas esta anchura máxima está ligeramente desplazada hacia la parte posterior. Las comisuras laterales son rectimarginadas, mientras que la comisura frontal puede ser de rectimarginada a surcada. El foramen es siempre circular y de muy pequeño tamaño. El umbo peduncular está fuertemente recurvado hacia la valva braquial. Se observa un surco medio en la valva braquial que presenta un desarrollo desigual: en las formas de contorno más circular este surco puede manifestarse a lo largo de prácticamente toda la valva. En los individuos ovalados, el surco tiende a desaparecer hacia la mitad posterior. En las formas juveniles, el surco apenas si está esbozado. Se observa un desarrollo diferente de las líneas de crecimiento en los ejemplares cordiformes y en los ovalados: en los primeros, estas líneas se manifiestan netamente en los últimos estadios de crecimiento, y en los segundos, se desarrollan sobre la práctica totalidad de la superficie de la concha. En el caso de los ejemplares de los cortes de Talveila, Honrubia de la Cuesta y La Ventosa del Ducado, las líneas de crecimiento presentan un desarrollo mucho más notable que el que se observa en los individuos de las localidades restantes.

Caracteres internos. El estudio de los caracteres internos de la especie $C$. davidsoni fue llevado a cabo mediante la realización de secciones seriadas en cinco ejemplares que corresponden a las morfologías ovaladas (cuersensis) y acorazonadas (davidsoni, Figs. 2A y B, respectivamente). El collar peduncular está presente y bien definido en algunos ejemplares. Las placas deltidiales están fusionadas formando un sinfitio. Las paredes de la parte posterior de la concha están engrosadas, especialmente en el ejemplar MU-9B/7 (Fig. 2A). El proceso cardinal tiene un desarrollo desigual: en algunos casos está más elevado con respecto a la valva braquial que en otros, pero siempre muestra una superficie denticulada. No existe cavidad umbonal. Las placas cardinales son cóncavas con respecto a la valva peduncular. Esta concavidad es mayor en el ejemplar MU-9B/7 (Fig. 2A). Las placas cardinales se prolongan en uno de sus extremos por las bases crurales, que pueden ser más o menos anchas. En su otro extremo, las placas se continúan con los rebordes internos de las fosetas, que están bien diferenciados, y en los que se insertan los dientes cardinales. Se observan también fosetas y dentículos accesorios. Los procesos crurales pueden ser desde subparalelos a ligeramente oblicuos. La bandeleta transversal es subhorizontal en el ejemplar figurado y convexa hacia la valva peduncular en los restantes. Se puede observar la presencia de un falso septo en la valva braquial como consecuencia del desarrollo de las impresiones de los músculos aductores. La existencia del surco medio externo en esta valva provoca que este septo sea observado con mayor nitidez.

\section{Lámina I}

1 Cuersithyris gijonensis (Dubar, 1925). PR-12/2. Ejemplar adulto de contorno pentagonal. Zona Jamesoni, Subzona Taylori.

2-7 Cuersithyris davidsoni (Haime, 1855). 2a-c, O/L $2 / a / 6$; ejemplar adulto, seccionado, con morfología ovalada y surco medio muy desarrollado. Zona Jamesoni. 3a-c, CVI-173/3; ejemplar adulto, seccionado, cordiforme, con gran desarrollo del surco medio dorsal. Zona Jamesoni. 4a-c, TV-34.67/3; ejemplar adulto, "estriado", con morfología cordiforme y desarrollo de surco medio dorsal. Anchura máxima situada en la parte media de la concha. Zona Jamesoni. 5a-c, PR-102/2; ejemplar adulto, cordiforme, con comisura frontal surcada. Zona Jamesoni, Subzona Jamesoni. $6 a-c$, MU9B/7; ejemplar adulto, seccionado, umbo recurvado, gran desarrollo del surco medio dorsal y comisura frontal surcada. Zona Jamesoni, Subzona Jamesoni. 7ac, CU-160/2; ejemplar juvenil, de contorno redondeado, comisura frontal rectimarginada y surco muy marcado. Zona Jamesoni.

8-13 Cuersithyris radstockiensis (Davidson, 1876). 8a-c, PR-77/6, ejemplar juvenil, alargado, con comisura frontal rectimarginada y umbo muy recurvado. Zona Jamesoni, Subzona Brevispina. 9a-c, 2CV-234/31, ejemplar adulto, seccionado, contorno ovalado, líneas de crecimiento marcadas y comisura frontal rectimarginada. Zona Jamesoni. 10a-c, 2CV-232/12, ejemplar adulto, de gran tamaño, con umbo muy recurvado y gran espesor. Zona Jamesoni. 11a-c, CU$170 / 1$, ejemplar adulto, seccionado, con gran espesor y fuerte desarrollo de las líneas de crecimiento, foramen muy pequeño y umbo fuertemente recurvado. Zona Ibex. 12a-c, CU-162/9, ejemplar adulto, ovalado, con comisura frontal rectimarginada y umbo recurvado. Zona Ibex. 13a-c, 2CV-234/68, ejemplar adulto, ovalado, con estrías muy desarrolladas y comisura frontal rectimarginada. Zona Jamesoni.

Todos los ejemplares a tamaño natural. $\mathrm{a}=\mathrm{vista}$ dorsal; $\mathrm{b}=\mathrm{vista}$ lateral; $\mathrm{c}=\mathrm{vista}$ frontal. 
Lámina I

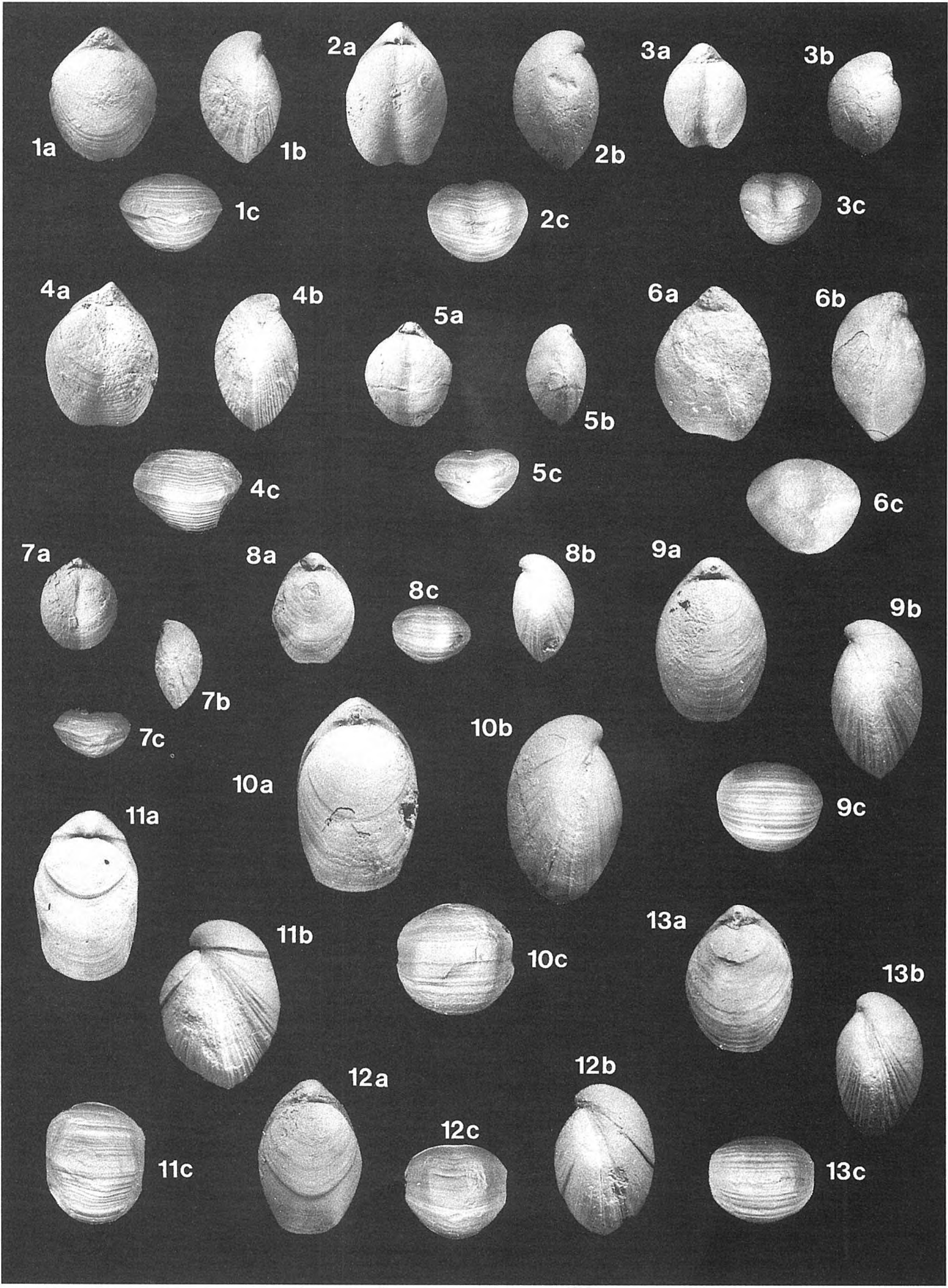

Revista Española de Paleontología, 13 (1), 1998. 


\begin{tabular}{||c|c|c|c|c|c|c|c||}
\hline \hline PR & Total & Máx. & mín. & M-m & X & $\delta$ & R \\
\hline L & 83 & 28,13 & 14,54 & 13,59 & 21,38 & 3,20 & \\
\hline A & 83 & 21,48 & 11,88 & 9,30 & 16,84 & 2,03 & 0,76 \\
\hline E & 83 & 18,30 & 6,16 & 12,14 & 13,21 & 2,52 & 0,71 \\
\hline \hline CV & Total & Máx. & mín. & M-m & X & $\delta$ & R \\
\hline L & 38 & 30,67 & 13,70 & 16,97 & 21,07 & 3,43 & \\
\hline A & 38 & 22,51 & 10,90 & 11,61 & 16,64 & 3,14 & 0,86 \\
\hline E & 38 & 17,26 & 8,05 & 9,21 & 12,46 & 2,37 & 0,68 \\
\hline \hline TV & Total & Máx. & mín. & M-m & X & $\delta$ & R \\
\hline L & 14 & 34,30 & 14,94 & 19,36 & 25,37 & 4,40 & \\
\hline A & 14 & 24,81 & 10,82 & 13,99 & 19,57 & 3,35 & 0,93 \\
\hline E & 14 & 20,17 & 9,38 & 10,79 & 15,49 & 2,68 & 0,86 \\
\hline \hline CU & Total & Máx. & mín. & M-m & X & $\delta$ & R \\
\hline L & 52 & 34,33 & 9,34 & 24,99 & 24,11 & 6,64 & \\
\hline A & 52 & 25,01 & 8,84 & 16,15 & 17,40 & 4,12 & 0,94 \\
\hline E & 52 & 22,55 & 4,47 & 18,08 & 13,92 & 4,51 & 0,96 \\
\hline \hline HO & Total & Máx. & mín. & M-m & X & $\delta$ & R \\
\hline L & 71 & 32,10 & 14,10 & 18,00 & 24,84 & 3,64 & \\
\hline A & 71 & 26,90 & 13,11 & 13,79 & 19,78 & 3,09 & 0,69 \\
\hline E & 71 & 20,00 & 6,42 & 13,58 & 14,05 & 2,99 & 0,77 \\
\hline \hline OL & Total & Máx. & mín. & M-m & X & $\delta$ & R \\
\hline L & 55 & 33,80 & 17,30 & 16,50 & 25,67 & 3,26 & \\
\hline A & 55 & 25,60 & 15,00 & 10,60 & 20,32 & 2,23 & 0,65 \\
\hline E & 55 & 20,00 & 7,87 & 12,13 & 15,14 & 2,92 & 0,92 \\
\hline \hline MU & Total & Máx. & mín. & M-m & X & $\delta$ & R \\
\hline L & 23 & 31,38 & 17,42 & 13,96 & 26,50 & 3,36 & \\
\hline A & 23 & 26,00 & 14,09 & 11,91 & 20,22 & 3,16 & 0,81 \\
\hline E & 23 & 18,85 & 8,14 & 10,71 & 15,20 & 2,52 & 0,86 \\
\hline
\end{tabular}

Tabla 1. Datos estadísticos del total de la muestra de Cuersithyris davidsoni (336 ejemplares). Máx.= valor máximo; mín.= valor mínimo; $\mathrm{x}=$ media; $\delta=$ desviación típica y $\mathrm{R}=$ coeficiente de correlación.

\section{Análisis biométrico}

Con el fin de caracterizar esta especie mediante relaciones dimensionales se han realizado gráficos L/A y $\mathrm{L} / \mathrm{E}$ que incluyen el total de los ejemplares de $C$. davidsoni (Tabla 1) identificados en todas las localidades de la Cordillera Ibérica y en la localidad tipo de la especie (Sa Moleta). En cada gráfico (Figs. 3A y B) se ha representado la línea de regresión correspondiente al total de los ejemplares de la especie, así como las líneas de los ejemplares de $C$. davidsoni en cada localidad. Puede observarse que la distribución de la nube de puntos para el gráfico L/A (Fig. 3B) puede ajustarse a una ecuación del tipo $\mathrm{y}=\mathrm{ax}$, con $\mathrm{b}$ siempre menor que 1 . La dispersión de los valores de L y A es homogénea, con excepción de algunos valores extremos correspondientes a ejemplares de $\mathrm{HO}$ que se alejan ligeramente de la distribución global. La tendencia de las curvas de regresión para el diagrama L/E (Fig. 3A) es algo diferente a la de L/A; además, en el gráfico $\mathrm{L} / \mathrm{E}$ el valor del exponente b es próximo a la unidad. En cualquier caso, la pendiente es también positiva y se observa una superposición de las curvas de regresión de las localidades de Almonacid y Honrubia. La curva de regresión

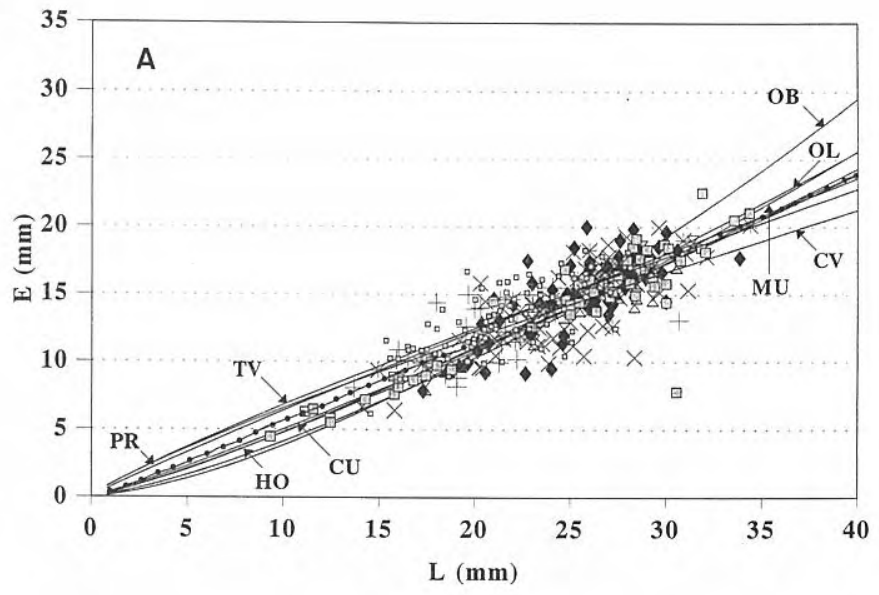

PR $+\mathrm{CV} * \mathrm{TV} \square \mathrm{CU} * \mathrm{HO} \diamond \mathrm{OL} \triangle \mathrm{OB}$ \& $\mathrm{MU} \odot \mathrm{TOTAL}$

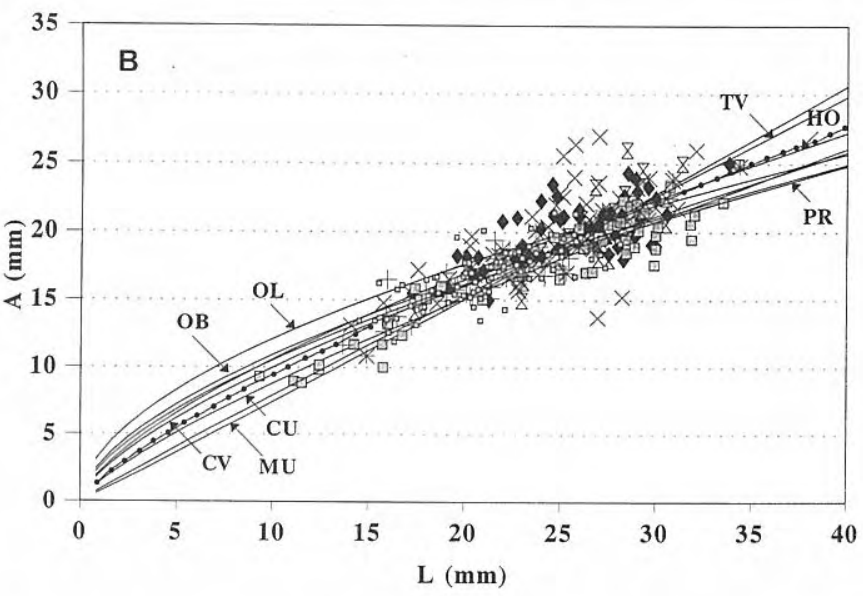

Figura 3. Gráficos de dispersión L/E (A) y L/A (B) para el total de la muestra de Cuersithyris davidsoni. $\mathrm{PR}=$ Préjano, $\mathrm{CV}=$ Castrovido, TV=Talveila, $\mathrm{CU}=\mathrm{Almonacid}$ de la Cuba, OL=La Ventosa del Ducado, $\mathrm{HO}=$ Honrubia de la Cuesta, $\mathrm{OB}=$ Obón, $\mathrm{MU}=\mathrm{Sa}$ Moleta.

correspondiente al total de la muestra (representada por una línea de puntos) llega a solaparse en el gráfico L/E (Fig. 3A) con las curvas correspondientes a las localidades de PR, TV, HO y CU. En el gráfico L/A (Fig. 3B) la curva del total se superpone prácticamente con la curva de OL. La distribución de longitudes abarca un intervalo bastante extenso, desde los 9,00 a los 35,00 mm, aproximadamente. Los valores medios de las variables son: $\mathrm{L}=24,32 \mathrm{~mm} ; \mathrm{A}=$ $18,58 \mathrm{~mm} ; \mathrm{E}=14,11 \mathrm{~mm}$.

En cuanto a los valores de los coeficientes de correlación (Tabla 1), los más altos se obtienen en la muestra de Almonacid de la Cuba (52 ejemplares), siendo de 0,94 para la relación L/A y de 0,96 para L/E. Los ejemplares de la localidad tipo, representados por la recta $\mathrm{MU}$ en los dos gráficos, dan valores de $\mathrm{R}$ que indican un buen ajuste de los datos a la ecuación de la recta $(\mathrm{R}=0,81$ para la relación $\mathrm{L} / \mathrm{A}$ y $\mathrm{R}=0,86$ para $\mathrm{L} / \mathrm{E})$. En las restantes localidades, los valores de $\mathrm{R}$ son más variables y oscilan entre 0,65 y 0,93 ; el 
caso extremo de valores no óptimos de correlación es el que se produce en la Ventosa del Ducado, con $\mathrm{R}=0,65$ para la relación $\mathrm{L} / \mathrm{A}$ y $\mathrm{R}=0,72$ para la relación $\mathrm{L} / \mathrm{E}$. En general, y con excepción de la localidad de Préjano, los valores más altos del coeficiente de correlación corresponden siempre a la relación $\mathrm{L} / \mathrm{E}$. Los valores de $\mathrm{R}$ para el total de los ejemplares considerados son de 0,83 para la relación L/A y de 0,82 para L/E.

\section{Observaciones y discusión}

Desde que en 1855 Haime creara la nueva especie Terebratula davidsoni han sido muchos los autores que han citado y/o figurado esta especie en sucesivos trabajos relacionados con el Jurásico Inferior. Las figuras originales de Haime (Lám. 15, figs. 6a,b,c y d) han planteado numerosos problemas a la hora de identificar esta especie, puesto que en ellas se muestran cuatro vistas, dos laterales y dos dorsales, de lo que supuestamente son dos ejemplares de $T$. davidsoni. Uno de ellos concuerda con la forma tipo definida por Haime, ya que presenta un surco central muy marcado y un contorno típicamente cordiforme; el otro, sin embargo, es un ejemplar de longitud mayor, morfología pentagonal y sin manifestación aparente de surco medio, lo que llevó a Alméras y Moulan (1982) a considerarlo como perteneciente a su nuevo género Cuersithyris y a la especie Cuersithyris gijonensis (Dubar, 1925). No obstante, hemos comprobado que la especie $C$. gijonensis no aparece nunca simultáneamente con las morfologías figuradas por Haime y, además, tampoco ha sido hallada, hasta el momento, en Mallorca (Comas-Rengifo y Rodrigo, 1995). Esto nos ha llevado a incluir esta figura en la sinonimia de la especie Cuersithyris davidsoni.

Otro de los problemas que se plantearon a partir del trabajo de Haime fue el hallazgo de formas, con una posición estratigráfica similar a la establecida por este autor en 1855 para su nueva especie, que no se ajustaban exactamente al tipo de la especie $T$. davidsoni. De entre ellas, cabe destacar las figuradas por Dubar (1925, Lám. 3, figs. 25, 26 y 27; 1931, Lám. 5, figs. 1-4), que corresponden a ejemplares procedentes de los Pirineos, con una morfología en unos casos más ovalada y, en otros, más deprimida dorsoventralmente que la establecida por Haime para su especie. Este hecho, unido al estudio de los caracteres internos de dos ejemplares cordiformes cedidos por M.J. Comas-Rengifo, hizo que Alméras y Moulan (1982) creyeran resuelto el problema de la variabilidad de esta especie, considerándola como próxima a Lobothyris por su estructura interna. Estos dos ejemplares son idénticos en cuanto a su morfología externa al tipo figurado por Haime y fueron atribuidos por estos autores a la especie Terebratula (Lobothyris?) davidsoni. Y dentro del nuevo género Cuersithyris incluyeron como especie tipo a Cuersithyris cuersensis, definida en la localidad de Cuers (Francia). Esta nueva especie corresponde, a nuestro parecer, a las mismas formas definidas por Haime, entrando dentro de la variabilidad de lo que nosotros hemos llamado Cuersithyris davidsoni; se ha mantenido, pues, el nuevo género creado por Alméras y Moulan (op. cit.), pero se ha respetado por su prioridad el nombre de la especie creada por Haime.

El establecimiento de la nueva especie Cuersithyris cuersensis Alméras y Moulan (1982) para el Jurásico Inferior francés y su separación de $C$. davidsoni (Haime, 1855) ha planteado numerosos problemas a la hora de su identificación. Ambos autores consideraron que la morfología davidsoni correspondía, no ya a una forma diferente dentro del género Cuersithyris, sino a una especie que podría ser incluida en función de sus caracteres internos dentro del género Lobothyris. Y en su sinonimia, refirieron la figura 1, Lám. 102 de Goy (1974) a C. cuersensis. Sin embargo, en 1990, Alméras y Faure citaron esta misma figura como perteneciente a la especie C. davidsoni aceptando, pues, su inclusión en este género y su separación del género Lobothyris. De manera que el problema de la asunción de las morfologías cuersensis y davidsoni como especies separadas no se solucionó con esta rectificación.

Esta especie se caracteriza por presentar un contorno que puede variar desde cordiforme a ovalado, una comisura frontal generalmente surcada y un surco medio en la valva dorsal. Se diferencia de $C$. gijonensis y $C$. radstockiensis por presentar menor longitud y valor del índice E/A. Los valores medios de la anchura son menores que los de $C$. gijonensis y mayores que los de $C$. radstockiensis. Por lo que respecta al espesor, por término medio es ligeramente mayor que el de $C$. gijonensis. En cuanto a los caracteres internos, presenta callosidades umbonales en la valva peduncular, proceso cardinal con superficie denticulada, placas cardinales situadas a una distancia más variable de la valva braquial que en $C$. gijonensis y $C$. radstockiensis y desarrollo de un falso septo.

En relación a la comparación de nuestro material con las figuraciones de los diferentes autores que aparecen en la sinonimia, se puede decir que la figura 5 de Deslongchamps (1862, Lám. 37), corresponde a un ejemplar juvenil de $C$. davidsoni en el que apenas está marcado el surco medio dorsal, mientras que la figura 9 de la misma lámina muestra, sin embargo, un ejemplar de contorno cordiforme y surco en la valva dorsal.

Los ejemplares figurados por Dubar (1925, Lám. 3, figs. 25-27, y Lám. 4, figs. 3-7) están muy mal conservados, aunque en ellos pueden reconocerse los caracteres externos típicos de la especie; las figs. 3-7 corresponden a individuos juveniles de $C$. davidsoni. Las figuras de Dubar (1931, Lám. 5, figs. 1-4) corresponden también a la especie, y cabe destacar que la figura 4 es idéntica a las formas con líneas de crecimiento más desarrolladas que se han identificado en los cortes de Honrubia de la Cuesta y La Ventosa del Ducado.

Las figuras 8, 10 y 11 de Choffat (1947, Lám. 4) corresponden a ejemplares recogidos en la localidad tipo de la especie. En concreto, la figura 8 muestra un gran parecido con las figuras $6 \mathrm{~b}$ y $6 \mathrm{c}$ de Haime (1855); la figura 9 corresponde a un ejemplar más alargado y con menor desarrollo del surco, mientras que la figura 10 muestra un individuo con un surco dorsal muy poco marcado. Esta última forma es similar a las figuras $6 a$ y 
$6 \mathrm{~d}$ de Haime (op. cit.), sobre todo en vista lateral, y se atribuye a la especie $C$. davidsoni. Nosotros no hemos encontrado morfologías cordiformes y con tan escaso desarrollo del surco central en individuos adultos, pero es muy probable que esta forma entrase en la variabilidad de la especie $C$. davidsoni. Habría que estudiar sus caracteres internos para corroborar esta posibilidad.

Los ejemplares figurados por Alméras y Moulan (1982, Lám. 1, figs. 1-10 y Lám. 2, fig. 15), bajo la denominación de $C$. cuersensis son, en general, muy próximos a las morfologías ovaladas y con fuerte desarrollo de las líneas de crecimiento que se han encontrado en las localidades de HO, OL y TV, y que hemos atribuido a la especie $C$. davidsoni, dado que sus caracteres internos no parecen diferir sustancialmente entre ambas morfologías.

\section{Distribución estratigráfica y geográfica}

España: base del Jurásico Inferior de Cataluña (Dubar, 1931). Cordillera Ibérica: en el Pliensbachiense inferior (Zona Jamesoni) del Sector Septentrional (Préjano, Castrovido y Talveila); Rama Castellana (Honrubia de la Cuesta y La Ventosa del Ducado); y Rama Aragonesa (Almonacid de la Cuba, Obón y Ricla). En el Jurásico Inferior de Mallorca (Haime, 1855; Colom, 1975). Francia: base del Jurásico Inferior de Normandía. En el Pliensbachiense inferior (Zona Jamesoni) de Var (Cuers y Rocbaron) y Pichauris (Alméras y Moulan, 1982). En Pirineos (Dubar, 1931).

\section{Cuersithyris radstockiensis (Davidson, 1876) Lám. I, figs. 8-13}

pars 1862 Terebratula subovoides, Deslongchamps (non Roemer), Lám. 37, figs. 4,6; Lám. 38, figs. 1, 5 $6,8$.

pars 1862 Terebratula punctata Deslongchamps (non Sowerby), Lám. 40, fig. 8.

pars 1876 Terebratula punctata Sowerby var. haresfieldensis Davidson, Lám. 16, fig. 9.

* 1876 Terebratula punctata Sowerby var. radstockiensis Davidson, Lám. 16, figs. 14-16, 18.

1905 Terebratula radstockiensis Davidson; Rau, p. 310; Lám. 3, figs. 7-10.

1925 Terebratula davidsoni var. gibbosa; Dubar, p. 295-296; Lám. 3, figs. 11-23.

1925 Terebratula davidsoni Haime var. elongata; Dubar, p. 294-295; Lám. 3, fig. 24.

1925 Terebratula cf. davidsoni Haime; Dubar, Lám. 4, figs. 1-2.

non 1929 Terebratula radstockiensis Davidson: Lanquine, p. 140; Lám. 2, fig. 11.

1947 Terebratula riberoi Choffat, forma radstockiensis Davidson; Choffat, Lám. 2, figs. $26,27$.

pars 1947 Terebratula davidsoni Haime; Choffat, Lám. 4, fig. 9.

1948 Terebratula davidsoni Haime var. elongata Dubar; Charles, p. 102, Lám. 8, fig. 4.

\begin{tabular}{||c|c|c|c|c|c|c|c||}
\hline PR & Total & Máx. & mín. & M-m & X & $\delta$ & R \\
\hline L & 153 & 36,00 & 13,50 & 22,50 & 21,59 & 5,12 & \\
\hline A & 150 & 26,03 & 10,70 & 15,33 & 16,42 & 3,43 & 0,93 \\
\hline E & 153 & 22,4 & 7,93 & 14,47 & 13,42 & 3,39 & 0,91 \\
\hline \hline CV & Total & Máx. & mín. & M-m & X & $\delta$ & R \\
\hline L & 79 & 44,30 & 19,18 & 25,12 & 27,41 & 4,08 & \\
\hline A & 79 & 23,93 & 14,96 & 8,97 & 20,27 & 2,19 & 0,77 \\
\hline E & 79 & 22,81 & 10,39 & 12,42 & 16,67 & 2,78 & 0,80 \\
\hline \hline CU & Total & Máx. & mín. & M-m & X & $\delta$ & R \\
\hline L & 30 & 35,80 & 19,00 & 16,80 & 30,06 & 4,11 & \\
\hline A & 30 & 25,90 & 14,31 & 11,59 & 20,73 & 2,23 & 0,63 \\
\hline E & 30 & 24,21 & 10,76 & 13,45 & 20,09 & 2,64 & 0,87 \\
\hline
\end{tabular}

Tabla 2. Datos estadísticos del total de la muestra de Cuersithyris radstockiensis (262 ejemplares). Máx.= valor máximo; mín. $=$ valor mínimo; $\mathrm{x}=$ media; $\delta=$ desviación típica y $\mathrm{R}=$ coeficiente de correlación.

1948 Terebratula davidsoni var. radstockiensis Davidson; Charles, p. 102, Lám. 8, fig. 5.

1948 Terebratula davidsoni Haime; Charles, p. 101102; Lám. 8, fig. 3.

1964 Terebratula davidsoni var. elongata y var. gibbosa (Dubar); Alméras, p. 89.

1974 Terebratula davidsoni (Haime) var. elongata Dubar; Goy, p. 743; Lám. 102, fig. 4.

1982 Cuersithyris radstockiensis (Davidson) morfotipo elongata Dubar; Alméras y Moulan, Lám. 1, fig. 16; Lám. 2, figs. 1-3,4,6,7 y 16.

1982 Cuersithyris radstockiensis (Davidson) morfotipo gibbosa Dubar; Alméras y Moulan, Lám. 1, figs. 14,15 y 17; Lám. 2, figs. 8-13.

non 1990 Lobothyris punctata edwardsii (Davidson); Ager, Lám. 1, fig. 7; Lám. 2, fig. 1.

1990 Lobothyris radstockiensis (Davidson); Ager, Lám. 2, figs. 2a-c, 3.

1991 Cuersithyris radstockiensis (Davidson); Alméras et al., p. 7 y 9 .

1993 Cuersithyris radstockiensis (Davidson); Alméras, p. 17.

Ejemplar tipo: Es un lectotipo escogido por Alméras y Moulan (1982). Corresponde a un ejemplar del Jurásico Inferior de Huish Quarry, cerca de Radstock (Gran Bretaña), figurado por Davidson, 1876, Lám. 16, fig. 14.

\section{Material}

El estudio de la especie Cuersithyris radstockiensis se ha realizado sobre un total de 266 ejemplares repartidos en tres localidades de la Cordillera Ibérica: Préjano, Castrovido y Almonacid de la Cuba (Tabla 2). Todo el material estudiado está depositado en el Departamento de Paleontología, Facultad de Ciencias Geológicas (UCM).

\section{Descripción}

Caracteres externos. C. radstockiensis corresponde a una forma de terebratúlido de longitud generalmente grande, desde 13,50 mm en un ejemplar de Préjano, hasta 44,30 mm 


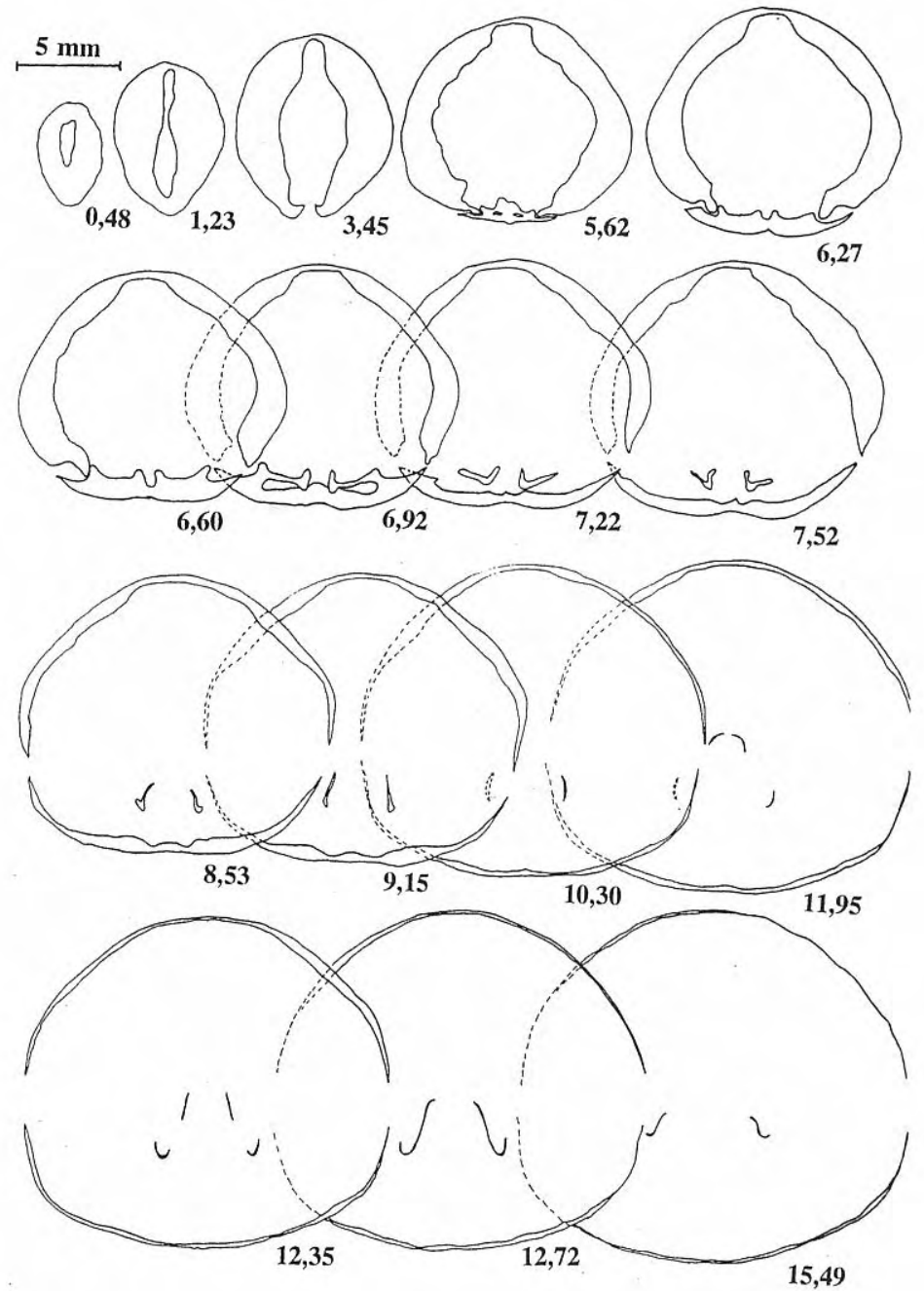

A
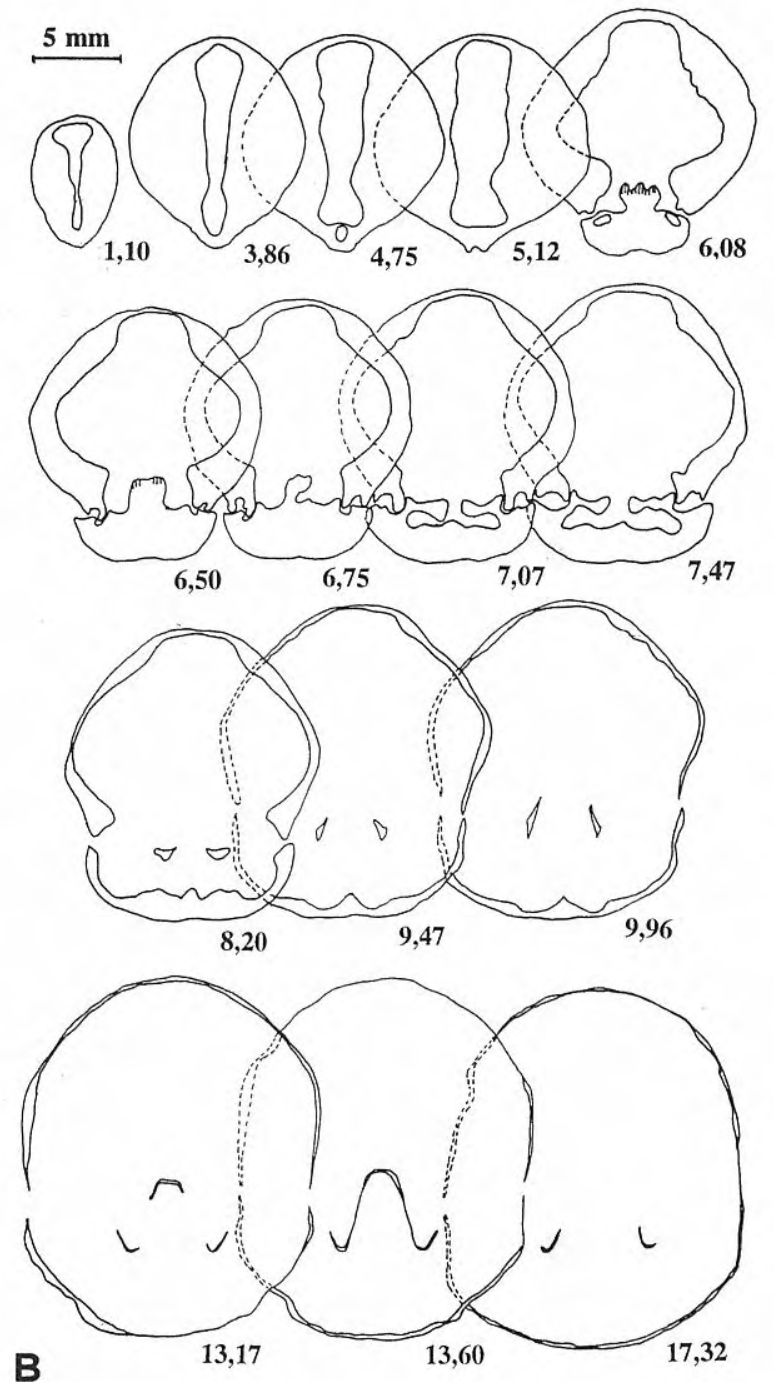

Figura 4. Cuersithyris radstockiensis. A: Secciones seriadas del ejemplar 2CV-234/31. Castrovido (Burgos). Zona Jamesoni; B: Secciones seriadas del ejemplar CU-170/1. Almonacid de la Cuba. Zona Ibex.

en otro de Castrovido. El contorno tiende a ser ovalado, tanto en los individuos juveniles como en las formas adultas. La convexidad de las valvas es desigual, con tendencia a un abombamiento más acusado de la valva braquial frente a la peduncular. Las comisuras laterales son subrectilíneas, y la comisura frontal, rectimarginada. La anchura máxima se sitúa hacia la mitad de la longitud de la concha. El foramen es pequeño, circular, aunque cuando el umbo se encuentra desgastado puede parecer de mayor tamaño. El umbo está fuertemente recurvado hacia la valva braquial, de modo que llega a ocultar el deltidio. El contorno en sección transversal es de subcircular a circular. En vista frontal, el aspecto de las valvas es truncado, de manera que la convexidad de la concha aumenta bruscamente hacia los laterales. No existe surco medio en la valva braquial. La ornamentación está constituida por líneas concéntricas que presentan un gran desarrollo.

Caracteres internos. (Figs. 4A y B). La región umbonal de la concha está muy engrosada (Fig. 4B). El proceso cardinal es de bilobulado a trilobulado. En este último caso, se encuentra muy diferenciado de la valva dorsal y en una posición elevada con respecto a ella. Las placas cardinales suelen ser largas, inclinadas hacia la valva dorsal y cóncavas con respecto a la valva peduncular. Los dientes cardinales son de sección rectangular y se insertan profundamente en las fosetas. Existen dentículos y fosetas accesorias. Los procesos crurales tienden a ser divergentes. La bandeleta transversal es prácticamente subhorizontal o convexa ventralmente. Falso septo medio más o menos desarrollado en la valva dorsal.

\section{Análisis biométrico}

Se ha estudiado un total de 266 ejemplares (Tabla 2). A partir de los datos biométricos se han obtenido diagramas de dispersión (Figs. 5A y B) en los que se puede observar un cierto agrupamiento por tamaños, de manera que los individuos más pequeños corresponden a Préjano y los más grandes a Almonacid de la Cuba. En el diagrama L/A (Fig. 5B), la distribución de la nube de puntos se ajusta a una curva de regresión de tipo potencial, con pendiente positiva. Los ejemplares con un tamaño inferior a $13 \mathrm{~mm}$, aproximadamente, no están representados en el total de la muestra de $C$. radstockiensis. La media global de las tres variables representadas es: $\mathrm{L}=27,87 \mathrm{~mm} ; \mathrm{A}=19,20 \mathrm{~mm}$; $\mathrm{E}$ 
$=17,91 \mathrm{~mm}$. Estos tres valores medios son superiores a los de $C$. davidsoni, con excepción de la anchura, que es similar. Los valores de los coeficientes de correlación (Tabla 2) indican un buen ajuste de los datos, sobre todo en la localidad de Préjano $(\mathrm{R}=0,93$ para la relación $\mathrm{L} / \mathrm{A}$ y $\mathrm{R}=0,91$ para la relación $\mathrm{L} / \mathrm{E})$. Los valores de $\mathrm{R}$ para el total de los ejemplares de la especie son: $\mathrm{R}=0,92$ para la relación $\mathrm{L} / \mathrm{E}$ y $\mathrm{R}=0,91$ para $\mathrm{L} / \mathrm{A}$.

\section{Observaciones y discusión}

En la actualidad, existen dos lectotipos propuestos para esta especie: por un lado, el designado por Almèras y Moulan (1982) y, por otro, el que propone Ager (1990). Ambos tipos proceden del trabajo de Davidson (1876), correspondiendo el primero a la fig. 14 de la Lám. 16 y el segundo a la fig. 15 de la misma lámina. Según Ager (op.cit.), el tipo original de Davidson (1876, Lám. 16, fig. 4)) no aparece en las colecciones del British Museum.

Como se puede ver en la sinonimia, dentro de la especie $C$. radstockiensis se han reconocido tradicionalmente dos morfotipos, elongata y gibbosa. En nuestra opinión, esta distinción no implica ninguna connotación subespecífica, ya que entre nuestros ejemplares se encuentran casi todas las morfologías intermedias entre ambos extremos y en los mismos niveles. La especie $C$. radstockiensis se caracteriza por presentar unas longitudes medias mayores que $C$. gijonensis y $C$. davidsoni, y una anchura menor que la que se observa en ambas especies (Fig. 6). Los valores de los índices E/A y $\mathrm{E} / \mathrm{L}$ son siempre más altos en radstockiensis que en las otras dos especies atribuidas al género Cuersithyris. La presencia de contorno ovalado y alargado, de una comisura frontal con frecuencia rectimarginada, y la ausencia de un surco medio en la valva dorsal (aunque sí se observa una pequeña depresión en el tercio anterior de dicha valva) distinguen esta especie de C. gijonensis (Lám. I, fig. 1) y de C. davidsoni (Lám. I, figs. 2-7).

Desde el punto de vista de los caracteres internos, $C$. radstockiensis se caracteriza por la presencia de un proceso cardinal plurilobulado, mayor engrosamiento de la valva peduncular en la región umbonal, mayor desarrollo de las impresiones de los músculos aductores en la valva dorsal (y, por tanto, del falso septo), y por un braquidio, en general, más largo.

Los ejemplares de $C$. radstockiensis recogidos en la Cordillera Ibérica muestran una gran proximidad morfológica con los figurados por Davidson (1876). Las figuras de Dubar (1925), realizadas a partir de ejemplares procedentes del Jurásico Inferior de los Pirineos franceses, son análogas a nuestras formas más gruesas. Con respecto a las figuras de Alméras y Moulan (1982), en general presentan unas dimensiones algo menores a las de nuestros ejemplares y unas líneas de crecimiento aparentemente menos marcadas.

\section{Distribución estratigráfica y geográfica}

España: En el Pliensbachiense inferior de la Cordillera Ibérica (Zona Jamesoni y base de la Zona Ibex): Sector Septentrional (Préjano, Castrovido y Talveila); Rama Aragonesa (Almonacid de la Cuba). Mallorca: Jurásico
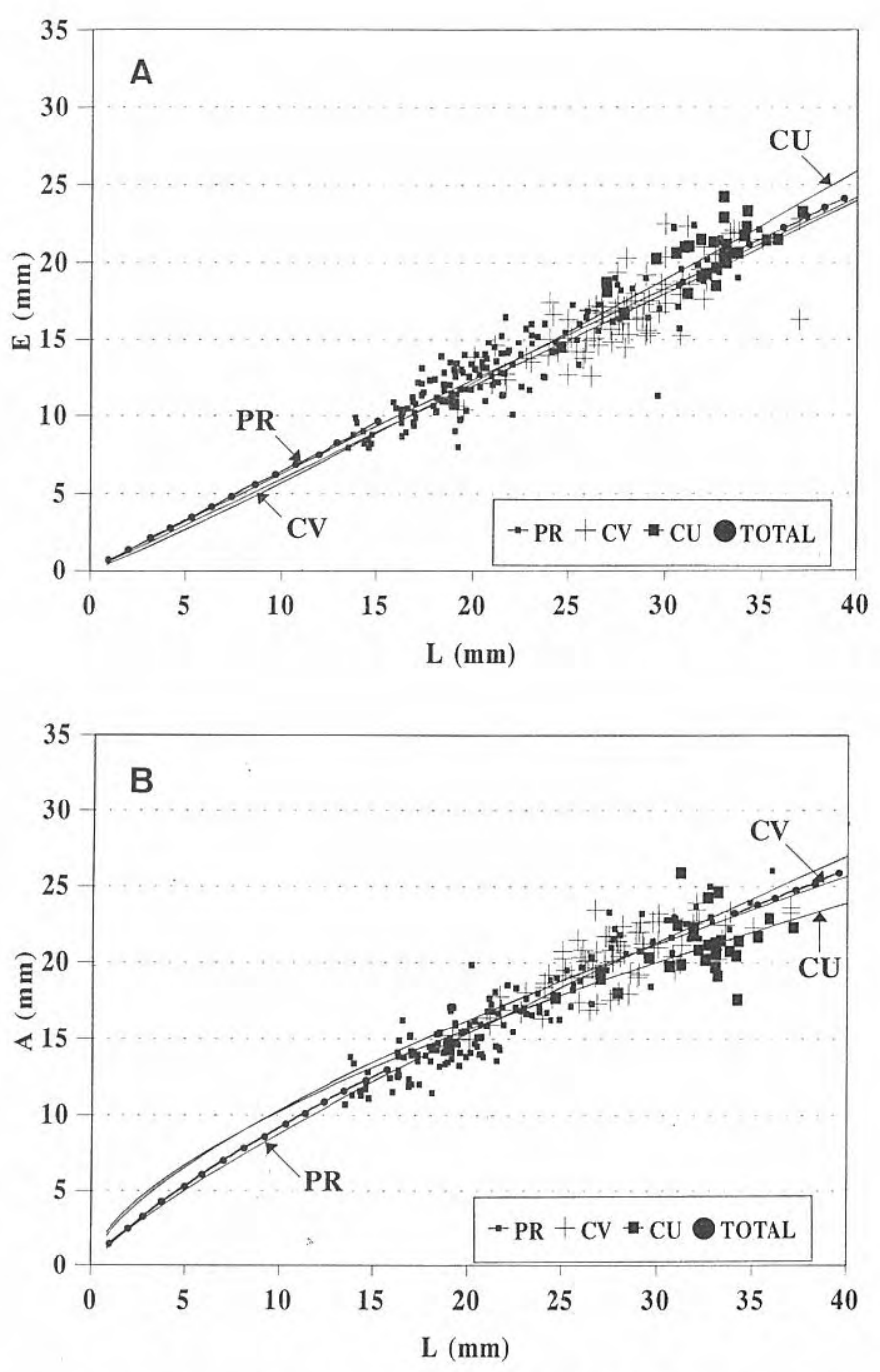

Figura 5. Gráficos de dispersión L/E (A) y L/A (B) para el total de la muestra de Cuersithyris radstockiensis. $\mathrm{PR}=$ Préjano, $\mathrm{CV}=$ Castrovido, $\mathrm{CU}=\mathrm{Almona}-$ cid de la Cuba.

Inferior. Portugal: Pliensbachiense inferior de Peniche. Gran Bretaña: Jurásico Inferior de los alrededores de Radstock. Francia: Jurásico Inferior de Normandía y en la Zona Jamesoni de los Pirineos (al este de Corbières y de Ariège). En la Zona Jamesoni de la localidad de Var; en Cuers, Rocbaron, Belgenter, Solliès-Ville, La Valette y Sanary.

\section{PALEOBIOGEOGRAFÍA}

Durante el Sinemuriense la distribución espacial de las especies de braquiópodos parece estar restringida a cualquiera de los dos dominios paleobiogeográficos establecidos por Delance (1974) y Vörös (1982a y b): el Dominio alpino, mediterráneo o del Tetis, que comprende los Alpes, Italia, Sicilia SE de España y parte del norte de África (Argelia), o el Dominio celto-suabo, que se extiende por el resto de Europa central y occidental y que también incluye parcialmente al norte de África. Esta gran dispersión de los braquiópodos lleva aparejada una 
A C. davidsoni

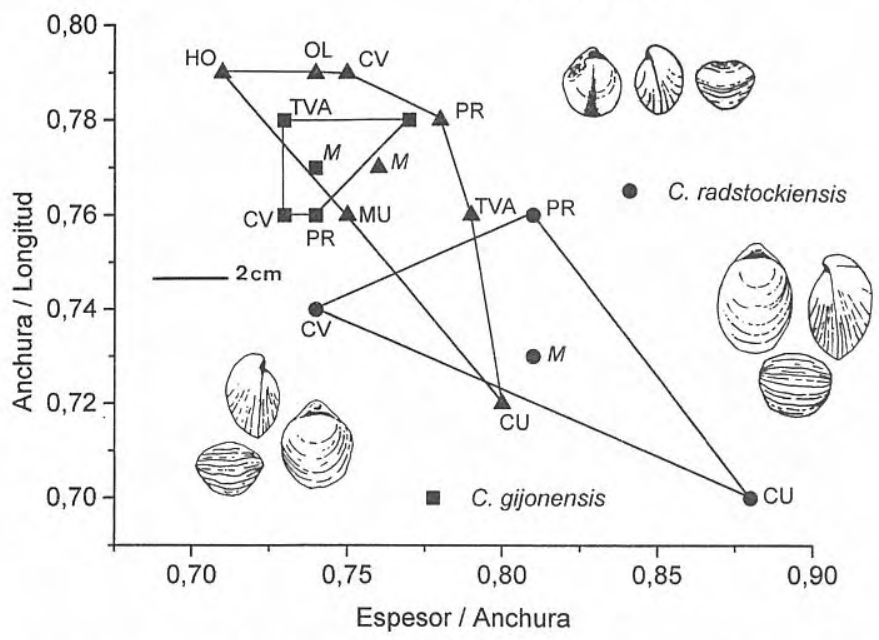

Figura 6. Gráfico que muestra la relación entre la anchura relativa $(\mathrm{A} / \mathrm{L})$ y la sección transversal $(\mathrm{E} / \mathrm{A})$ de las morfologías más características de las especies en cada una de las localidades estudiadas. Los puntos señalados con siglas indican los valores medios de los índices en las localidades a que hacen referencia. M=media de las variables consideradas.

gran dificultad a la hora de establecer correlaciones a gran escala. Sin embargo, en el Pliensbachiense inferior tales correlaciones son más fáciles de establecer porque las asociaciones de braquiópodos se solapan en los límites de sus áreas de distribución (Delance, 1974). Para Alméras y Elmi (1982), las fluctuaciones de las faunas podrían estar controladas por variaciones batimétricas que producirían durante el Pliensbachiense inferior un aislamiento de las poblaciones de braquiópodos.

Durante el intervalo temporal SinemuriensePliensbachiense se registra la presencia del género Cuersithyris en España (Baleares, Cataluña, Cordillera Ibérica y Asturias), Portugal (Peniche), Francia (Causses, Var y Provenza) y Gran Bretaña (Radstock). Las especies de este género han sido utilizadas frecuentemente en diversas propuestas de biozonación en distintas cuencas de Europa Occidental (Fig. 7). Es el caso de las realizadas por
Goy (1974), Goy et al. (1984) y Alméras et al. (1991) para la Cordillera Ibérica y Francia, mientras que no parecen estar presentes en áreas más septentrionales (Revert, 1971; Tchoumatchenco, 1971). Este hecho parece coincidir con la idea de Almèras y Moulan (1982), según la cual las faunas de braquiópodos sufren, durante este intervalo temporal, un proceso de aislamiento entre las regiones meridional y septentrional del Domino Boreal.

En la Cordillera Ibérica, los primeros braquiópodos identificados (Goy et al., 1984) corresponden al Sinemuriense superior (Zona Raricostatum) de la localidad de Préjano ( $\mathrm{N}$ de la Cordillera Ibérica). Durante el Pliensbachiense inferior se registran numerosas especies de braquiópodos, algunas de ellas nuevas y otras ya presentes en el Sinemuriense (Comas-Rengifo y Rodrigo, 1995). Todas las asociaciones de braquiópodos registradas en el Jurásico Inferior de la Cordillera Ibérica para el intervalo Sinemuriense-Pliensbachiense inferior pertenecen a la denominada Provincia Europea (Ager, 1967).

\section{CONCLUSIONES}

El análisis estadístico realizado con el conjunto de los datos biométricos obtenidos, la observación de caracteres morfológicos cualitativos (tales como el mayor o menor desarrollo del surco medio de la valva dorsal, la* presencia/ausencia de un aplastamiento en la región anterior o la intensidad en el recurvamiento del umbo peduncular), así como el estudio de los caracteres internos (presencia de callosidades umbonales, morfología del proceso cardinal, grado de inclinación y desarrollo de las placas cardinales, ausencia de cavidades umbonales, existencia de dentículos y fosetas accesorias, aspecto e inclinación de los procesos crurales y de la bandeleta transversal, y presencia de un falso septo), han permitido la caracterización de las especies Cuersithyris radstockiensis y Cuersithyris davidsoni. En este sentido, y a tenor de las características internas y externas que presenta la especie Cuersithyris davidsoni, así como en función de su distribución geográfica, se ha considerado como una especie independiente que incluye en su variabilidad las formas atribuidas hasta este momento a la

\begin{tabular}{|c|c|c|c|c|c|c|c|}
\hline $\begin{array}{l}\text { ZONACIÓN } \\
\text { AMMONITES }\end{array}$ & $\begin{array}{c}\text { CAUSSES } \\
\text { (REVERT, 1971) }\end{array}$ & $\begin{array}{c}\text { BULGARIA } \\
\text { (TCHOUMAT., 1971) }\end{array}$ & $\begin{array}{c}\text { CORDILLERA } \\
\text { IBÉRICA } \\
\text { (GOY, 1974) }\end{array}$ & \multicolumn{2}{|c|}{$\begin{array}{l}\text { CORDILLERA IBÉRICA } \\
\text { (GOY } \text { et al., 1984) }\end{array}$} & \multicolumn{2}{|c|}{$\begin{array}{c}\text { FRANCIA } \\
\text { (ALMÉRAS et al., 1991) }\end{array}$} \\
\hline ZONA & ZONA & ZONA & FAUNIZONA & ZONA & SUBZONA & ZONA & SUBZONA \\
\hline DAVOEI & C. briseis & Z. cornuta & \multirow{4}{*}{$\begin{array}{l}\text { "T". gr. } \\
\text { davidsoni }\end{array}$} & \multirow{3}{*}{ NUMISMALIS } & \multirow{2}{*}{ Darwini } & $\begin{array}{l}\text { Rudirhynchia } \\
\text { rudis }\end{array}$ & \\
\hline \multirow{2}{*}{ IBEX } & \multirow{2}{*}{ G. curviceps } & \multirow{4}{*}{ "T". dunrobinensis } & & & & & $\begin{array}{l}\text { Gibbirhynchia } \\
\text { curviceps }\end{array}$ \\
\hline & & & & & Doridsoni & Gibbirhynchia & Cuersithyris \\
\hline JAMESONI & \multirow[t]{2}{*}{ "T". tetrahedra } & & & \multirow{2}{*}{ DUNROBINENSIS } & & & $\begin{array}{c}\mathrm{y} \\
\text { Cuersithyris } \\
\text { radstockiensis }\end{array}$ \\
\hline RARICOSTATUM & & & & & & & \\
\hline
\end{tabular}

Figura 7. Biozonación estándar para las cuencas del suroeste de Europa durante el intervalo Sinemuriense superiorPliensbachiense inferior. 
especie Cuersithyris cuersensis Alméras y Moulan, 1982. La inclusión de C. davidsoni dentro del género Cuersithyris se ha realizado teniendo en cuenta las características del género, es decir, valvas de convexidad desigual, comisuras laterales rectilíneas, comisura frontal surcada, foramen circular de pequeño tamaño y umbo recurvado; presencia de callosidades umbonales, collar peduncular relativamente corto (normalmente denticulado en superficie), placas cardinales más o menos inclinadas y un falso septo.

La distribución estratigráfica del género abarca desde el Sinemuriense superior (Zona Raricostatum) hasta el Pliensbachiense inferior (base de la Zona Ibex, Subzona Masseanum). La primera especie que aparece es $C$. gijonensis (Zona Raricostatum), cuya distribución nunca sobrepasa la Zona Jamesoni (Subzona Brevispina). A continuación, y con excepción del corte de Almonacid de la Cuba, la siguiente especie registrada es $C$. radstockiensis en la Zona Jamesoni, Subzona Brevispina, aunque en Préjano alcanza la base de la Zona Ibex (Subzona Masseanum). La última especie registrada es $C$. davidsoni, que aparece en algunos niveles simultáneamente con $C$. radstockiensis. Su rango estratigráfico abarca desde la Zona Jamesoni (Subzona Jamesoni) hasta la Zona Ibex (Subzona Masseanum). De este modo, se puede observar que la distribución estratigráfica de este género es muy restringida, lo cual ha permitido la utilización de la especie C. davidsoni como índice zonal.

Desde el punto de vista del contexto paleogeográfico en el que se sitúa la Cordillera Ibérica durante el Pliensbachiense inferior, se detectan condiciones de plataforma abierta, probablemente bien oxigenada y con un alto contenido en nutrientes, que favorecen la colonización e instalación de diversas faunas de braquiópodos, entre ellas de los representantes del género Cuersithyris. La súbita desaparición del registro fósil de este género, producida a comienzos del Pliensbachiense inferior, podría estar relacionada con un cambio brusco en las condiciones ambientales. Durante el intervalo Sinemuriense-Pliensbachiense, todas las asociaciones de braquiópodos que se conocen en la Cordillera Ibérica son típicamente boreales y pertenecen a la denominada Provincia Europea (Ager, 1967).

\section{AGRADECIMIENTOS}

Las autoras agradecen al Dr. M. de Renzi y a la Dra. C. Herrero sus sugerencias sobre este trabajo, así como al Dr. Jenaro García-Alcalde su exhaustiva labor de revisión que ha mejorado sustancialmente el trabajo. Las fotografías han sido realizadas por Uly Martín y la delineación por Andrés Correa. Este trabajo ha sido realizado dentro de los Proyectos PB91-0380 y PB93-0459.

\section{BIBLIOGRAFÍA}

Ager, D.V. 1967. Some Mesozoic Brachiopods in the Tethys Region. In: Aspects of Tethyan Biogeography (Eds. C.G.
Adams and D.V. Ager). Systematics Association, Publication $n^{\circ}$ 7, 135-151.

Ager, D.V. 1990. British Liassic Terebratulida (Brachiopoda). Palaeontographical Society, 1, 1-39.

Alméras, Y. 1964. Brachiopodes du Lias et du Dogger. Essai bibliographique et critique de paléontologie stratigraphique. Documents Laboratoire Géologique Lyon, 5, 1-161.

Alméras, Y. 1993. The Liassic Brachiopod Zones of the Middle-Atlas, Morocco, comparaison with the French North Tethyan zonation. In: Mesozoic Brachiopods of Alpine Europe (Eds. J. Palfy and A. Vörös). Hungarian Geological Society, 15-21.

Alméras, Y. et Elmi, S. 1982. Fluctuations des peuplements d'ammonites et de brachiopodes en liaison avec les variations bathymétriques pendant le Jurassique inférieur et moyen en méditerranée occidentale. Bolletino della Società Paleontologica Italiana, 21 (2-3): 169-188.

Alméras, Y. et Faure, P. 1990. Histoire des Brachiopodes liasiques dans la Tethys occidentale: les crises et l'écologie. Cahiers Université Catholique Lyon, Série Sciences, 4, 1-12.

Alméras, Y. et Moulan, G. 1979. Biostratigraphie des Terebratulidae et des Zeilleridae du Lias et de Nord de la Région Toulonaisse (Var, France). Géobios, 12, 893897.

Alméras, Y. et Moulan, G. 1982. Les Térébratulides liasiques de Provence. Paléontologie, Biostratigraphie, Paleoécologie, Phylogenie. Documents Laboratoires de Géologie de la Faculté des Sciences de Lyon, 86, 1-365.

Alméras, Y., Boullier, A. et Laurin, B. 1991. Les Zones de Brachiopodes en France. Annales Scientifiques de l'Université de Besançon, Series Geologie, 10, 3-30.

Álvaro, M., Barnolas, A., del Olmo, P., Ramírez del Pozo, J. y Simo, A. 1984. Estratigrafía del Jurásico. In: Sedimentología del Jurásico de Mallorca (Ed. A. Barnolas-Cortinas). I.G.M.E.-C.G.S., 43-71.

Álvaro, M., Barnolas, A., Cabra, P., Comas-Rengifo, M.J., Fernández López, S., Goy, A., Del Olmo, P., Ramírez del Pozo, J., Simo, A. y Ureta, S. 1989. El Jurásico de Mallorca (Islas Baleares). Cuadernos de Geología Ibérica, 13, 67-120.

Buckman, S.S. 1917. The Brachiopoda of the Namyau Beds, Northern Shan States, Burma. Palaeontologia Indica, N.S., 3 (2), 1-299.

Charles, R.P. 1948. Le Lias de la Basse Provence Occidentale. Étude paléontologique et paléobiologique. Unpublished Ph.D. Tesis, University of Aix-Marselle, 207 pp.

Choffat, P. 1947. Description de la Faune jurassique du Portugal. Brachiopodes. Memorias dos Serviços Geológicos de Portugal, 1-46.

Colom, G. 1975. Geología de Mallorca. Diputación Provincial de Baleares. Palma de Mallorca. 297 pp.

Comas-Rengifo, M.J. 1979. El Pliensbachiense en Castrovido (Burgos). Cuadernos de Geología, 10, 219-227.

Comas-Rengifo, M.J. 1985. El Pliensbachiense de la Cordillera Ibérica. Editorial de la Universidad Complutense, Madrid, 19/85, $591 \mathrm{pp}$.

Comas-Rengifo, M.J. y Goy, A. 1975. Estratigrafía y Paleontología de Ribarredonda (Guadalajara). Estudios Geológicos, 31, 297-339. 
Comas-Rengifo, M.J. y Goy, A. 1978. El Pliensbachiense y Toarciense en la Rambla del Salto (Sierra Palomera, Teruel). Guía de excursiones al Jurásico de la Cordillera Ibérica. Grupo Español del Mesozoico, Madrid, IV, 11 pp.

Comas-Rengifo, M.J. y Rodrigo, A. 1995. Cuersithyris gijonesis del Lías inferior y medio de la Cordillera ibérica (España). Boletín de la Real Sociedad Española de Historia Natural, Seccion Geología, 90, 69-85.

Comas-Rengifo, M.J. y Yébenes, A. 1988. El Lías al Sur de la Sierra de Urbión (Talveila, Soria). III Coloquio de Estratigrafía y Paleogeografía del Jurásico de España. Ciencias de la Tierra, 11, 149-165.

Comas-Rengifo, M.J., Goy, A. y Yébenes, A. 1988. El Lías en el Sector Suroccidental de la Sierra de la Demanda (Castrovido, Burgos). III Coloquio de Estratigrafía y Paleogeografía del Jurásico de España. Ciencias de la Tierra, 11, 119-141.

Davidson, T. 1876-78. A Monograph of the British Fossil Brachiopoda. Vol. 4, part. 2 (Jurassic and Triassic). Monograph of the Palaeontographical Society of London, $\mathrm{N}^{\mathrm{o}} 1$ (1876), 73-144; $\mathrm{N}^{\mathrm{o}} 2$ (1878), 145-242.

Delance, J.H. 1974. Zeilleridés du Lias d'Europe Occidentale. Mémoires Géologiques de l'Université de Dijon, 2, 1-408.

Deslongchamps, E.E. 1862-86. Études critiques sur des Brachiopods nouveaux ou peu connus. Art. 10: sur l'appareil brachial de diverses Térébratules du Lias et du Systéme Oolithique inférieur. Bulletin de la Société Linneanne de Normandie, Sér. 3 (7-8), 378 pp.

Dubar, G. 1925. Étude sur le Lias des Pyrénées Françaises. Mémoires de la Société Géologique du Nord, 9 (1), 1332.

Dubar, G. 1931. Brachiopodes liasiques de Catalogne et des régions voisines. Butlletí de la Institució Catalana d'Historia Natural, 4, 103-180.

García-Joral, F. 1986. Los Braquiópodos del Aaleniense de la Cordillera Ibérica. Tesis Doctoral, Universidad Complutense de Madrid, 326 pp. (Inédita).

García-Joral, F. y Goy, A. 1984. Características de la fauna de braquiópodos del Toarciense superior en el Sector Central de la Cordillera Ibérica (Noreste de España). Estudios Geológicos, 40, 55-59.

Gil, G. y Zubieta, J.M. 1978. Mapa Geológico de España. Esc. 1:50.000 ( $2^{\mathrm{a}}$ serie). Explicación de la Hoja $\mathrm{n}^{\circ} 277$, Salas de los Infantes (Burgos). I.G.M.E, $37 \mathrm{pp}$.

Goy, A. 1974. El Lías en la mitad Norte de la Rama Castellana de la Cordillera Ibérica. Tesis Doctoral Inédita, Universidad Complutense de Madrid, 940 pp.

Goy, A. y Robles, F. 1971. Resultado de un estudio sobre braquiópodos en el NE de Guadalajara. I Centenario de la Real Sociedad Española de Historia Natural, 1, 243255.

Goy, A. y Robles, F. 1975. El Jurásico de Turmiel (Guadalajara). Estudios Geológicos, 31, 261-283.

Goy, A., Comas-Rengifo, M.J. and García-Joral, F. 1984. The Liassic Brachiopods of the Iberian Range (Spain): Stratigraphic distribution and Biozonation. In: International Symposium on Jurassic Stratigraphy, Erlangen, September 1974 (Eds. O. Michelsen and A. Zeiss), 1, 227-250.
Haime, J. 1855. Notice sur la géologie de l'île Majorque. Bulletin de la Societé Géologique de France, $2^{\text {éme }}$ sèrie, 12, 734-752.

Lanquine, A. 1929. Le Lias et le Jurassique des chaînes provençales. Part. 1: Le Lias et le Jurassique inférieur. Bulletin de la Carte Géologique de France, 32 (173), 385 pp.

Mensink, H. 1965. Stratigraphie und paläogeographie des marinen Jura in den nord westlichen Iberischen Ketten (Spanien). Beihefte zum Geologischen Jahrbuch, 44, 55102.

Mouterde, R. 1971. Une coupe du Lias à Obón aux confins des provinces de Teruel et de Saragosse. Cuadernos Geología Ibérica, 2, 345-354.

Mouterde, R., Fernández-López, S., Goy, A., Linares, A., Rivas, P., Ruget, Ch. y Suárez-Vega, L.C. 1978. El Jurásico de la región de Obón (Teruel). Guía de Excursiones al Jurásico de la Cordillera Ibérica. Grupo Español Mesozoico, Madrid, II, 13 pp.

Muir-Wood, H.M. 1934. On the internal structure of some Mesozoic Brachiopoda. Philosophical Transactions of the Royal Society of London, Series B, 223, 511-567.

Rau, K. 1905. Die Brachiopoden des mittleren Lias Schwabens mit ausschluss der Spiriferinen. Geologische und Paläontologische Abhandlungen, 6 (5), 355 pp.

Revert, J. 1971. Les brachiopodes du Lias Moyen du bassin des Causses. Étude biostratigraphique. Géobios, 4, 199-221.

Rodrigo, A. 1994. Revisión del género Cuersithyris (Brachiopoda) del Lotharingiense superior y Carixiense en la Cordillera Ibérica. Tesis de Licenciatura, Facultad de Ciencias Geológicas, Universidad Complutense de Madrid. 199 págs. (Inédita).

San Miguel de la Cámara, M. 1951. La constitución geológica del anticlinal de Honrubia. Estudios Geológicos, 7 (14), 387-410.

Sequeiros, L., Cólera, I., Valenzuela, R. y Sánchez, I. 1978. Bioestratigrafía del Jurásico (Lías y Dogger) en el sector Belchite-Almonacid de la Cuba (provincia de Zaragoza, Cordillera Ibérica). Estudios Geológicos, 34, 293-298.

Soler-Olivé, N. 1986. Los Tetrarhynchiinae (Brachiopoda) del Pliensbachiense de la Cordillera Ibérica. Tesis de Licenciatura, Universidad Complutense de Madrid, 261 pp. (Inédita).

Suárez-Vega, L.C. 1974. Estratigrafía del Jurásico en Asturias. Cuadernos de Geología Ibérica, 3 vols., 369 pp.

Tchoumatchenco, P. 1971. Notes sur la repartition stratigraphique des brachiopodes du Jurassique dans les Balkanides centrales et occidentales (Bulgarie). Coll. du Jurassique. Louxembourg. Mémoires du Bureau de Recherches Géologiques et Minières, 75, 183-187.

Ureta, S. y Goy, A. 1986. El Aaleniense en el área de Talveila (Soria). Estudios Geológicos, 42, 331-339.

Vörös, A. 1982a. Lower and Middle Jurassic brachiopod provinces in the Western Tethys. Fóldtani Közlöny. Bulletin of the Hungarian Geological Society, 110, 395-416.

Vörös, A. 1982b. Stratigraphic evaluation of the Pliensbachian brachiopod fauna the Bakony Mts. (Hungary). Bulletin of the Hungarian Geological Society, 112, 351-361.

Manuscrito recibido: 4 de noviembre, 1996 Manuscrito aceptado: 22 de abril, 1997 